OPEN ACCESS

Edited by:

Natalia N. Nalivaeva,

University of Leeds, United Kingdom

Reviewed by:

Wang-Xia Wang,

University of Kentucky, United States

Aguennouz M'Hammed,

University of Messina, Italy

*Correspondence:

Bharani Thangavelu

bharani.thangavelu.ctr@mail.mil

Specialty section:

This article was submitted to

Neurodegeneration,

a section of the journal

Frontiers in Neuroscience

Received: 04 May 2020

Accepted: 07 August 2020

Published: 18 September 2020

Citation:

Thangavelu $B$, Wilfred $B S$ Johnson D, Gilsdorf JS, Shear DA and Boutté AM (2020) Penetrating

Ballistic-Like Brain Injury Leads to MicroRNA Dysregulation, BACE1 Upregulation, and Amyloid Precursor

Protein Loss in Lesioned Rat Brain

Tissues. Front. Neurosci. 14:915.

doi: 10.3389/fnins.2020.00915

\section{Penetrating Ballistic-Like Brain Injury Leads to MicroRNA Dysregulation, BACE1 Upregulation, and Amyloid Precursor Protein Loss in Lesioned Rat Brain Tissues}

\author{
Bharani Thangavelu ${ }^{1 *}$, Bernard S. Wilfred ${ }^{1}$, David Johnson ${ }^{2}$, Janice S. Gilsdorf ${ }^{1}$, \\ Deborah A. Shear ${ }^{1}$ and Angela M. Boutté ${ }^{1}$
}

'Brain Trauma Neuroprotection Branch, Center for Military Psychiatry and Neuroscience, Walter Reed Army Institute of Research, Silver Spring, MD, United States, ${ }^{2}$ Department of Pathology and Area Laboratory Services, Landstuhl Regional Medical Center, Landstuhl, Germany

Severe traumatic brain injury $(\mathrm{TBI})$ is a risk factor for neurodegenerative diseases. Yet, the molecular events involving dysregulated miRNAs that may be associated with protein degradation in the brain remains elusive. Quantitation of more than 800 miRNAs was conducted using rat ipsilateral coronal brain tissues collected 1,3 , or 7 days after penetrating ballistic-like brain injury (PBBI). As a control for each time-point, Sham-operated animals received craniotomy alone. Microarray and systems biology analysis indicated that the amplitude and complexity of miRNAs affected were greatest 7 day after PBBI. Arrays and Q-PCR inferred that dysregulation of miR-135a, miR328, miR-29c, and miR-21 were associated with altered levels of beta-site amyloid precursor protein cleaving enzyme 1 (BACE1), PSEN1, PSEN2, and amyloid precursor protein (APP) genes. These events were followed by increased levels of mature BACE1 protein and concomitant loss of full length APP within 3-7 days, then elevation of amyloid beta $(A \beta)-407$ days after PBBI. This study indicates that miRNA arrays, coupled with systems biology, may be used to guide study design prior validation of miRNA dysregulation. Associative analysis of miRNAs, mRNAs, and proteins within a proposed pathway are poised for further validation as biomarkers and therapeutic targets relevant to TBI-induced APP loss and subsequent A $\beta$ peptide generation during neurodegeneration.

Keywords: traumatic brain injury, neurodegenerative diseases, microRNA, amyloid precursor protein, beta-site amyloid precursor protein cleaving enzyme 1

\section{INTRODUCTION}

Severe traumatic brain injury (TBI) remains a significant health issue that leads to cognitive and physical impairment, prolonged hospitalization, and the need for long-term care (Langlois et al., 2005; Zaloshnja et al., 2008; Cuthbert et al., 2015; Taylor et al., 2017). Military personnel are at a particularly high risk for encountering a TBI (Santiago et al., 2012) due, in part, to improvised 
explosive devices and munition exposures (Meyer et al., 2010; Boutte et al., 2019). Patients who suffer from a TBI are at a much higher risk of developing neurodegenerative disease or dementia (Plassman et al., 2000), particularly Alzheimer's disease (AD) (Mendez et al., 2015), Parkinson's disease (PD) (Gardner et al., 2018), Amyotrophic lateral sclerosis (ALS) (Franz et al., 2019), psychological disorders (Veitch et al., 2013), post-traumatic stress disorder (PTSD) (FriedemannSanchez et al., 2008), and suicide (Goldstein and Diaz-Arrastia, 2018). The epidemiological basis for TBI as a risk factor for neurodegeneration is established, yet the molecular basis that may offer a connection between these two events remains difficult to discern. As such, development of effective, possibly preventative, therapeutic strategies remain challenging.

MicroRNAs (miRNAs), small, non-coding nucleotide sequences, approximately 18-25 nucleotides in length that play an integral role in the regulation of gene expression (Fabian et al., 2010). MiRNAs are implicated in neurodegenerative disorders (Eacker et al., 2009) and linked to increased cell death after brain injury (Truettner et al., 2013). A single miRNA is capable of regulating dozens, if not hundreds, of mRNA transcripts, or several miRNAs may be associated with key processes, thereby affecting a myriad of cellular processes, including inflammation (Khoshnam et al., 2017), cell death (Boone et al., 2017), as well as protein turnover or loss (Che et al., 2017) through direct or indirect interactions. Recent studies have indicated that miRNA levels are dysregulated in a host of neurodegenerative diseases and contribute to pathology (Nelson et al., 2008; Maciotta et al., 2013). A large number of miRNAs are associated with amyloid precursor protein (APP) degradation and subsequent amyloid beta $(\mathrm{A} \beta$ ) production (Schonrock et al., 2012), a pathological hallmark of amyloidopathies and neuronal loss (Karnati et al., 2015; He et al., 2018). TBI leads to widespread atrophy that is spurred, in part, by protein degradation, inclusive of full length APP loss and increased levels of A $\beta$ peptides (Purushothuman et al., 2013). Thus, it is possible that miRNAs may have a role as key mediators of trauma induced neurodegeneration associated with degradation of full length APP in the brain.

In the present study, we determined time-dependent quantitation profiles of miRNAs within ipsilateral rat brain tissues collected 1-7 days after penetrating ballistic-like brain injury (PBBI), a model of severe, open skull TBI. This model has been extensively characterized; several studies have found that key features are generally highest at 1, 3, or 7 days postinjury. For instance, blood brain barrier disruption is greatest within 1 day (Cunningham et al., 2014), while indices of inflammation, cell loss, and protein fragmentation are prominent at 3-7 days post-injury (Boutte et al., 2016, 2020; Cartagena et al., 2016; DeDominicis et al., 2018). Collectively, these features are involved in severe TBI progression for which miRNA may be involved.

Compared to controls, miRNAs were associated with wellknown effects of brain trauma, such as inflammation or neurodegeneration. A subset of miRNAs mapped specifically to genes within the APP-processing pathway, including betasite amyloid precursor protein cleaving enzyme 1 (BACE1), the gene that encodes beta $(\beta)$-secretase. These observations were associated with increased levels of mature BACE1, posttranscriptional APP loss, and upregulation of $\mathrm{A} \beta-40$ peptide levels in the PBBI model. Analysis of miRNA arrays and pathway mapping augment hypotheses regarding molecular events of TBI progression. More importantly, subsets of miRNAs, mRNAs, and proteins within a concerted pathway, such as APP processing, may provide novel therapeutic targets for TBI.

\section{MATERIALS AND METHODS}

\section{Surgical Procedures}

Male Sprague-Dawley rats weighing 250-300 g (Charles River Labs, Raleigh, VA, United States) were housed individually under a normal 12-h light/dark cycle (lights on at 6:00 am). Animals were anesthetized with $5 \%$ isoflurane delivered along with oxygen for surgery while body temperature was maintained at $37^{\circ} \mathrm{C}$ using a heating blanket (Harvard Apparatus, Holliston, MA, United States). Prior to euthanasia for bio-specimen collection, animals were anesthetized with $70 \mathrm{mg} / \mathrm{kg}$ ketamine and $6 \mathrm{mg} / \mathrm{kg}$ xylazine. Facilities at the Walter Reed Army Institute of Research (WRAIR) are accredited by the Association for Assessment and Accreditation of Laboratory Animal Care International (AAALAC). The experimental procedures were approved by the WRAIR Animal Care and Use Committee. Research was conducted in compliance with the Animal Welfare Act and other federal statutes and regulations relating to animals and experiments involving animals and adheres to principles stated in the Guide for the Care and Use of Laboratory Animals, NRC Publication, 2011 edition.

\section{Penetrating Ballistic-Like Brain Injury Rodent Model and Brain Tissue Collection}

The rodent PBBI model of severe TBI has been extensively characterized (Williams et al., 2005, 2006). The injury trajectory produces a cavity in the brain, mimicking the trajectory of a high-velocity bullet wound. This penetrating brain injury was performed as previously reported (Boutte et al., 2016). Briefly, induction of a $10 \%$ (brain volume) unilateral frontal PBBI was performed upon anesthetized rats by stereotaxic insertion of a specially designed probe into the right hemisphere of the brain (Mitre Corporation, McLean, VA, United States). The probe was inserted through a cranial window over the frontal cortex and rapid inflation/deflation of a water-filled balloon was used to create a temporary cavity in the cerebrum. Sham-operated rats received identical surgical procedures and craniotomy, without probe insertion or balloon inflation. Two millimeter thick coronal sections were dissected starting at 5 millimeters from bregma collected 1,3 , or 7 days after PBBI or Sham-operated procedures $(N=10 /$ group/timepoint). The ipsilateral hemisphere was immediately flash frozen in liquid nitrogen, and stored at $-80^{\circ} \mathrm{C}$ until use. Ipsilateral tissues are comprised of the injury core and 
perilesional injury zones of the cortical and subcortical regions, including the frontal cortex caudate-putamen as well as the corpus callosum.

\section{RNA Isolation and Reverse Transcription}

Total RNA was isolated from brain tissue samples with the mirVana RNA isolation kit, according to the manufacturer's protocol specifically modified for total RNA (Ambion Inc., Mississauga, ON, Canada). Content and quality was determined with the Nanodrop 1000 spectrophotometer (Thermo Scientific, Inc., Waltham, MA, United States). Samples were then stored at $-80^{\circ} \mathrm{C}$ until use for miRNA arrays or individual PCR of specific miRNAs or mRNAs.

\section{MiRNA Arrays}

MicroRNAs arrays were conducted as described by the Genetic Resources Core Facility at Johns Hopkins University using methodology provided directly by the manufacturer (Applied Biosystems of Thermo Fisher, Grand Island, NY, United States) as described (Grigorenko et al., 2011). Complementary (c) DNA for 821 target genes for the rodent miRNAs were prepared using $\mathrm{MegaPlex}^{\circledR}$ rodent primer pools A and B and arrays were conducted using the TaqMan Rodent Array Panel on the 12-Flex Open Array system (\#4461105, Life Technologies/Thermo Fisher, Grand Island, NY, United States). Global normalization was applied prior to further analysis (Mestdagh et al., 2009). Thereafter, the values of PBBI cohorts were compared to respective Shamoperated values to derive the $\Delta \Delta \mathrm{Ct}$ values. The derived relative quantitative values are reported using the formula for relative quantities $\mathrm{RQ}=2^{-\Delta \Delta \mathrm{Ct}}$. For each time-point, comparisons were constructed and plotted as $-\log _{2}$ fold change of PBBI versus Sham-operated $\left[-\log _{2}\right.$ (PBBI/Sham) $]$ compared to the $-\log _{10}$ ( $p$-value) with the Quant Studio12 $\mathrm{K}^{\mathrm{TM}}$ software v1.2.2 (Life Technologies/Thermo Fisher, Grand Island, NY, United States). The dataset is available within Supplementary Tables 1A-C.

\section{Quantitative PCR Assays}

Coding (c) DNA was generated using TaqMan miRNA Reverse Transcription primers $\left(16^{\circ} \mathrm{C}\right.$ for $30 \mathrm{~min}, 42^{\circ} \mathrm{C}$ for $30 \mathrm{~min}$, $85^{\circ} \mathrm{C}$ for $5 \mathrm{~min}$ ) specific for each miRNA or mRNA sequence. Each sample was tested in duplicate using the AB7500 Fast RT-PCR system (Life Technologies/Thermo Fisher, Grand Island, NY, United States). Relative quantities were calculated using the $\mathrm{RQ}=2^{-C t}$ method with mammU6 or $\beta$-actin as the endogenous reference genes for miRNA or mRNA, respectively. The Taqman assay identification numbers (IDs) for the miRNA or mRNA targets are listed as follows: miR-29c (TM000587), miR-328 (TM000543), and miR-135a (TM000460), miR-21 (TM000397, miR-21-5p) and miR-214 (TM000517), mammU6 (TM001973), APP (Rn01524846_m1), BACE1 (Rn00569988_m1), PSEN1 (Rn00569763_m1), PSEN2 (Rn00579412_m1), $\beta$-actin (Rn00667869_m1). For each time point, the PBBI values are displayed as a fold change (mean \pm SEM) from Sham-operated normalized to "1."

\section{Western Blotting}

Brain tissues were sonicated for $10 \mathrm{~s}$, three times each, in ice-chilled $1 \times$ RIPA lysis buffer, supplemented at 1/100 with Halt protease and phosphatase inhibitor mix (Sigma-Aldrich, St. Louis, MO, United States), followed by centrifugation at $10,000 \times g$ at $4^{\circ} \mathrm{C}$ for $20 \mathrm{~min}$. Clarified supernatant was collected and protein concentrations were determined using the Pierce Micro BCA protein assay kit (Thermo Fisher Scientific, Rockford, IL, United States). Samples were normalized to contain $5 \mu \mathrm{g}$ total protein $/ 5 \mu \mathrm{L} /$ lane prior to being separated by $4-$ $15 \%$ gradient PAGE with the NuPAGE system (Invitrogen of Thermo Fisher, Grand Island, NY, United States) (Eaton et al., 2013). After transferring to nitrocellulose membranes, blots were probed with anti-C-terminal APP antibody (\#A8717, Sigma, Allentown, PA, United States), or anti-BACE1 antibody (clone EPR19523, \#ab183612, Abcam, Cambridge, MA, United States). Densitometry of protein bands intensity was measured using the Li-COR Odyssey ${ }^{\circledR}$ CLx Imaging System (Li-COR Biosciences, Lincoln, NE, United States). Contrast was enhanced for visualization purposes only. For each time point, the PBBI values are displayed as a fold change from Sham-operated, which are normalized to equal " 1 ." Data is displayed as the fold change (mean \pm SEM).

\section{Electrochemiluminescent ELISAs}

Clarified supernatant containing $20 \mu \mathrm{g}$ of total protein was used to determine $A \beta-40$ and -42 peptide concentrations using the V-PLEX Kit (4G8-epitope) according to the manufacturer's instructions (Mesoscale, Rockville, MD, United States). Measurements were derived from electrochemiluminescent signal with a QuickPlex SQ120 (Meso Scale Discovery, Rockville, MD, United States) and quantitation was extrapolated from individual standard curves of each peptide. All assays were conducted in duplicate and RIPA lysis buffer was used as a negative control.

\section{Data Management and Statistical Analysis}

Array generated data was analyzed using QuantStudio Expression Suite ${ }^{\circledR}$ software package (Version 1.1) which calculates fold changes and $p$-values of each dataset at each time-point. MiRNA was mapped to direct interactions within the APP processing pathway using Pathways Studio Web with the Fisher's exact test (Version 12, Elsevier, Radarweg, Amsterdam, Netherlands). Relationships evidenced by at least one citation were retained. Static annotations and nomenclature are shown as defined by Pathway Studios. A $\beta$ peptides were noted as "proteins" by default and have been manually annotated as "peptides" for accuracy. Venn diagram analysis was performed using Venny (Version 2.1.1. MiRNA, mRNA, APP, and BACE1 protein levels were analyzed with the two-tailed, Student's $t$-Tests. Comparative $A \beta$ content were determined using two-way ANOVA, Fisher's LSD post-test.

\footnotetext{
${ }^{1}$ http://bioinfogp.cnb.csic.es/tools/venny/
} 


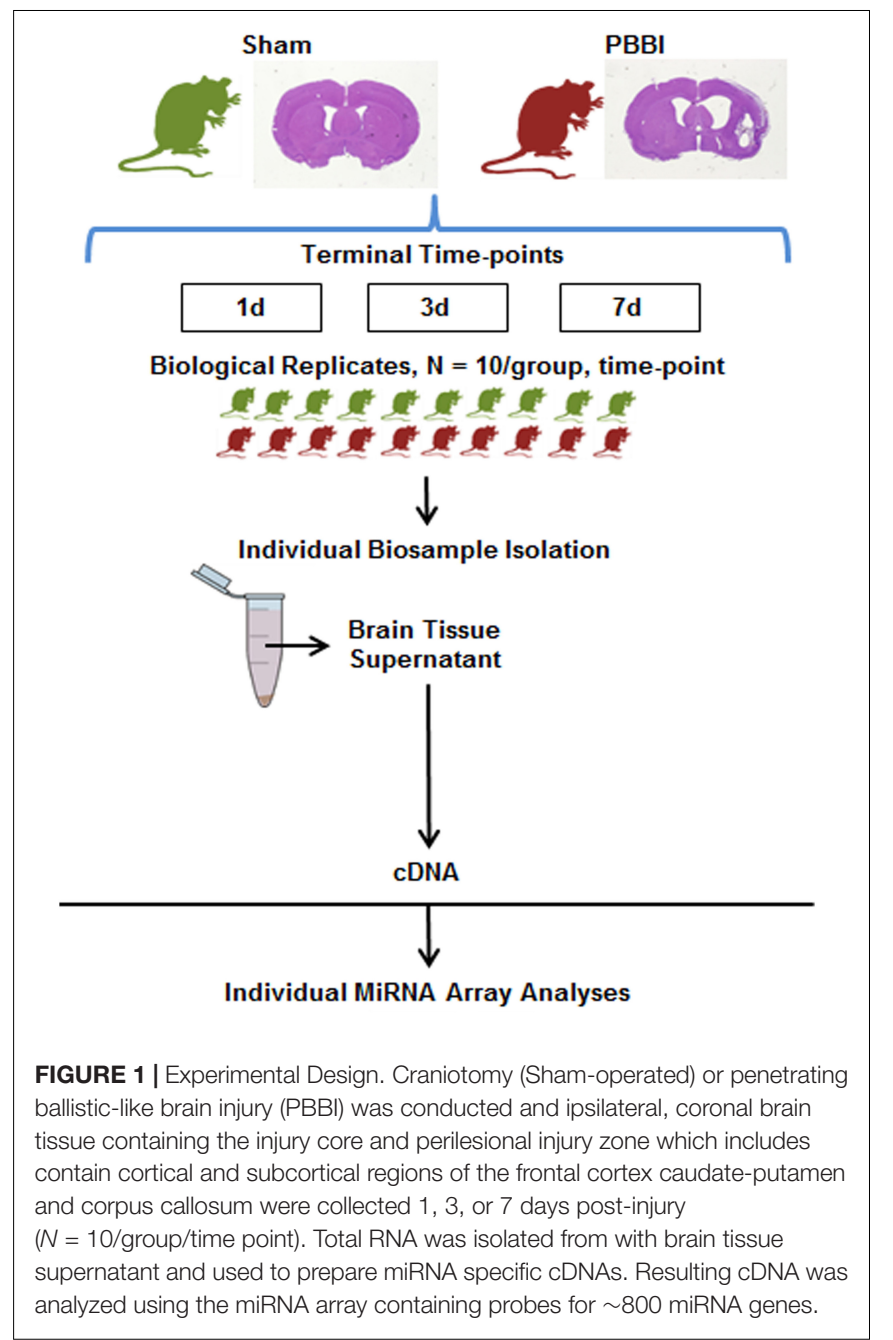

\section{RESULTS}

\section{Temporal miRNA Response in Brain Tissues After PBBI}

This study examined miRNA levels in coronal brain sections, derived from the ipsilateral hemisphere, at three time points after PBBI. The injury paradigm with the genomics workflow and schema is displayed (Figure 1). The miRNAs affected by injury over the time-points tested were differentiated using miRNA arrays. The effect upon miRNA differential abundance was determined using ipsilateral, coronal brain tissue sections collected after PBBI compared to Sham-operated controls. The number of miRNAs which were differentially abundant varied over time (Figure 2). A total of eight, seven, and 46 miRNAs were differentially expressed at 1 day (Table 1A), 3 day (Table 1B), and 7 day (Table 1C), respectively. Volcano plots indicating the fold changes and $p$-values for each miRNA tested are displayed for each time point (Figure 2A). A total of 58 sequences were found to be differentially affected by PBBI. A major shift in the magnitude of miRNA dysregulated was detected at 7 day after PBBI (31 upregulated, 12 downregulated) (Figure 2B). The vast majority of miRNAs that had a significant fold change were generally unique for each time point with the exception of a few sequences (Figure 2C). MiR-34b increased (1.70-fold) at 1 day, decreased 3 day (0.63-fold), but was similar to Shamoperated levels at 7 day. MiR-328, -335 , and -667 levels were unaffected by PBBI at 1 day, yet suppressed at 3-7 days (range: 0.63 to 0.83 -fold). Forms of miR-21 was increased at 1 and 7 days after PBBI. Specifically, mmu-miR-21 (miR-21\#, miR-21-3p) was increased after 1 day (2.90-fold), while hsa-miR-21 (e.g., miR21-5p) was increased at 7 day after PBBI (1.50-fold). MiR-223 was also elevated (3.30-fold) at 1 and 7 days. MiR-155 increased within 1 day (3.70-fold), but was slightly less robust (2.2-fold) 7 day after PBBI compared to Sham-operated controls. At 3 day after PBBI, levels of each of these miRNAs was similar to that of Sham-operated controls.

\section{MiRNAs and mRNAs Associated With the Amyloid Precursor Protein Pathway}

Next, this list of miRNAs was mapped to the "APP Processing" pathway in order to determine potential associative relationships to genes involved specifically in APP regulation or degradation, inclusive of down-stream generation of C-terminal fragments and $\mathrm{A} \beta$ peptides. The curated interaction as defined by Pathway Studios is shown for each time point (Figures 3A-C). At 1 day, miR-135A (downregulated) was negatively associated with PSEN1 and BACE1 that both converged upon APP via positive relationships (representing cleavage of the target by the enzyme or protease), and note that miR-223 (increased) is displayed with its inhibitory relationship to ADAM17, while ADAM10 has no direct miRNA relationships in this dataset (Figure 3A). Here, regulation of PSEN2 is shown in relation to PSEN1 based on pathways cited from the database. MiR-328 (downregulated) was also linked to BACE1 and APP through negative interactions derived from brain tissues collected at 3 day (Figure 3B). Interactions derived from brain tissues collected 7 day after PBBI indicate that miR-21 (upregulated), miR-29c (downregulated), and miR-328 (downregulated) were also directly linked to BACE1 and APP through inhibitory or inversely proportional relationships defined by Pathways Studio (Figure 3C). MiR-223 (upregulated) was again noted for its negative relationship to ADAM17. Additionally, MiR-214 (upregulated) was negatively associated with PSEN1, which is negatively linked to APP.

Although array analysis indicated that select miRNAs were significantly dysregulated at specific time points and associated with mRNAs, miRNAs and relevant mRNAs were evaluated across all time points in order to validate array results and to define the temporal effect (Figure 4). Q-PCR indicated that miR-29c, -328 , and -135 a were each elevated at 1 day (range: $2.08 \pm 0.17$ to $3.37 \pm 0.49$ ), then decreased to near Sham-operated levels 7 day after PBBI (Figure 4A). MiR-21$5 \mathrm{p}$ was for single tube, qPCR confirmation. MiR-21 decreased $(0.23 \pm 0.03)$ among PBBI groups compared to Sham-operated controls at 1 day, but was progressively increased over time (range: $2.83 \pm 0.56$ to $4.28 \pm 0.43$ ) among PBBI cohorts. Mir-214 was greatest 1 day $(5.91 \pm 1.80)$ and at 7 day $(18.1 \pm 3.92)$ after PBBI, but slightly less robust at 3 day $(1.66 \pm 0.25)$ (Figure $4 B$ ). 
A
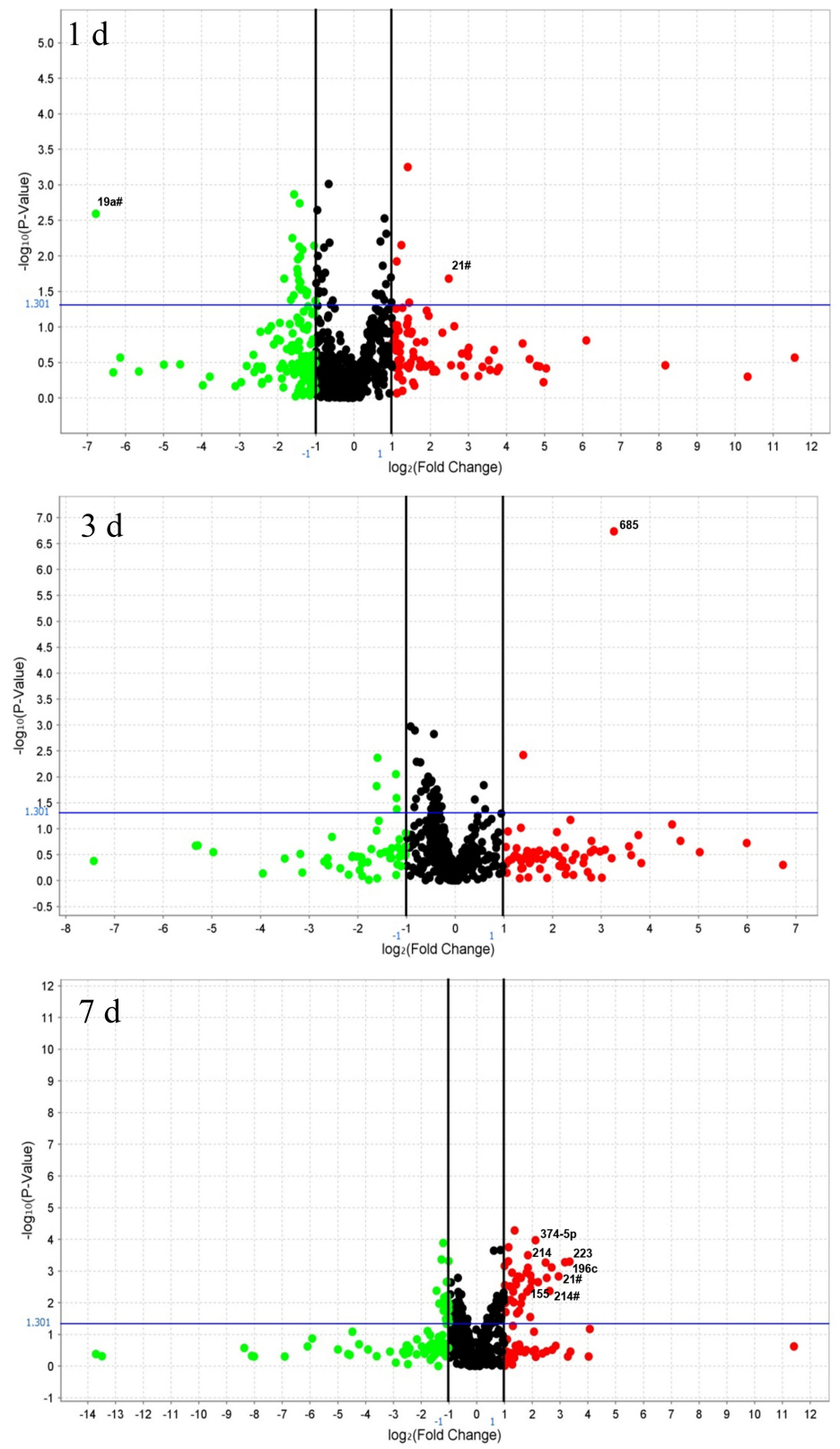

B

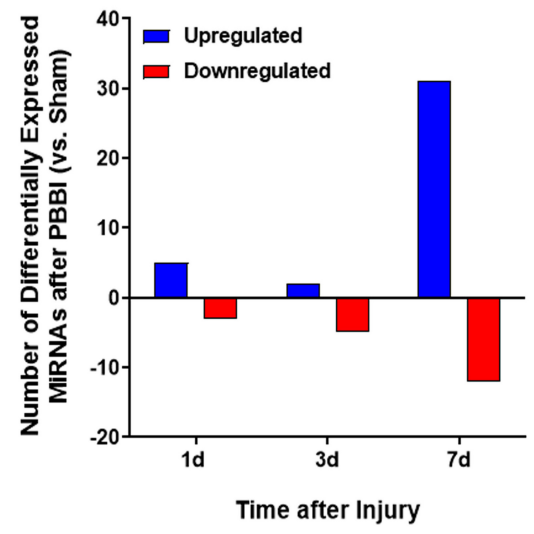

C

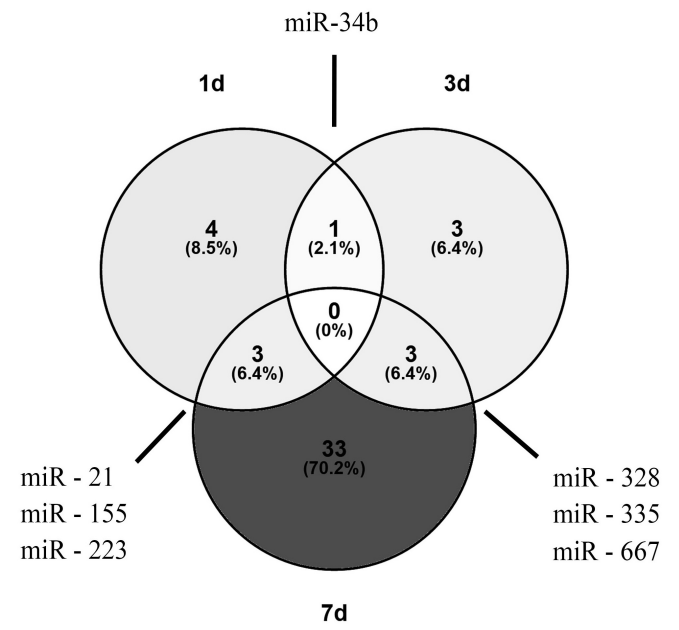

FIGURE 2 | Differential Abundance of MiRNAs after PBBI. Overview of MiRNAs Detected in Brain Tissues after PBBI. (A) Volcano plots of miRNA data derived from Life Technologies MiRNA microarray containing 821 unique probes. Data is shown for ipsilateral brain tissues collected 1 day (left), 3 day (center), and 7 day (right) after PBBI. All fold change values are normalized to Sham-operated controls. Data is displayed as the Log $_{2}$ ratio of PBBI/Sham ( $x$-axis) and the -Log 10 -value derived from two-tailed $t$-tests ( $y$-axis). Black vertical lines represent the $\log _{2}$ (PBBI/Sham) ratio of miRNAs that are decreased (green circles) or increased (red circles). MiRNAs with $\geq$ two-fold change are annotated. The horizontal blue line represents the - $\log _{10} p$-value cut-off at $p=0.05$. (B) Amplitude for each time point tested ( $x$-axis), the total number of upregulated (blue) or downregulated (red) miRNAs are displayed ( $y$-axis). (C) Venn diagram of differentially regulated miRNAs. The total number of differentially expressed miRNAs are indicated for each time-point. Overlap between time-points of specific miRNAs are indicated.

Next, mRNA levels of APP, BACE1, PSEN1, and PSEN2 were determined (Figure 4C). Interestingly, levels of APP mRNA were generally suppressed by PBBI compared to Sham-operated controls (range: $0.53 \pm 0.07)$. Further, BACE1 $(3.10 \pm 0.11)$, PSEN1 $(1.14 \pm 0.25)$, and PSEN2 (3.79 \pm 1.03$)$ mRNA levels each peaked 3 day after injury. PSEN1 was suppressed at 1 day $(0.42 \pm 0.05)$ and 7 day $(0.52 \pm 0.07)$ compared to Sham-operated controls. However, PSEN2 was similar to Shamoperated levels at these same time points (range: $1.34 \pm 0.22$ to $1.42 \pm 0.46)$. 
TABLE 1 | List of miRNAs that were increased or decreased in brain tissue isolated at (A) 1 day, (B) 3 day, and (C) 7 day after PBBI compared to Sham-operated controls over time as defined by Quant Studio.

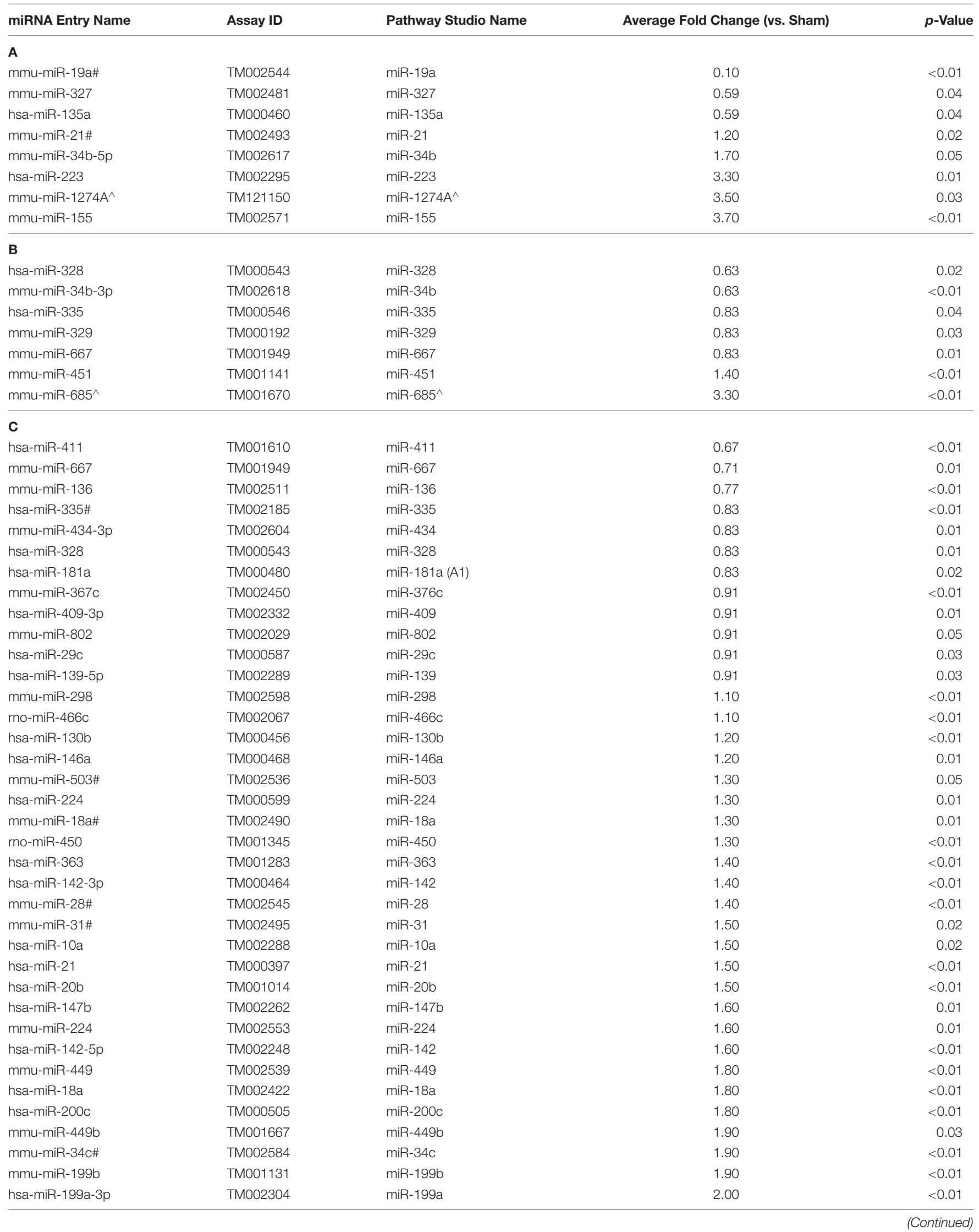


TABLE 1 | Continued

\begin{tabular}{|c|c|c|c|c|}
\hline miRNA Entry Name & Assay ID & Pathway Studio Name & Average Fold Change (vs. Sham) & $p$-Value \\
\hline mmu-miR-374-5p & TM001319 & miR-374 & 2.10 & $<0.01$ \\
\hline mmu-miR-155 & TM002571 & $\operatorname{miR}-155$ & 2.20 & $<0.01$ \\
\hline mmu-miR-214 & TM002306 & miR-214 & 2.50 & $<0.01$ \\
\hline hsa-miR-214 & TM000517 & $\operatorname{miR}-214$ & 2.50 & $<0.01$ \\
\hline hsa-miR-214\# & TM002293 & miR-214 & 2.60 & $<0.01$ \\
\hline hsa-miR-223 & TM002295 & miR-223 & 2.70 & $<0.01$ \\
\hline mmu-miR-21\# & TM002493 & $\operatorname{miR}-21$ & 2.90 & $<0.01$ \\
\hline rno-miR-196c & TM002049 & $\operatorname{miR}-196 c$ & 3.20 & $<0.01$ \\
\hline hsa-miR-223 & TM000526 & miR-223 & 3.30 & $<0.01$ \\
\hline
\end{tabular}

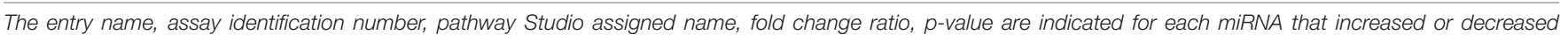

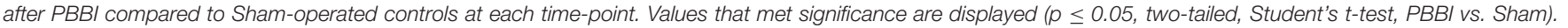
Non-regulatory sequences from RNase P RNA or TRNA are indicated with a caret symbol $(\wedge)$.

\section{Amyloid Precursor Protein Pathway Protein Levels}

Due to the increase in BACE1 and suppression of APP mRNA transcripts, protein levels were investigated (Figure 5). Western blotting detected both pro- and mature forms of BACE1 at $\sim 56$ and $\sim 50 \mathrm{kDa}$, respectively (Figure 5A, left). Quantitation indicated that pro-BACE1 protein levels increased at 1 day $(1.49 \pm 0.47)$, then decreased swiftly at 3 day $(0.53 \pm 0.06)$ or 7 day $(0.54 \pm 0.22)$ after PBBI (Figure $5 \mathbf{A}$, center). Mature BACE1 protein levels intensified at 3 day $(0.18 \pm 0.04)$ and 7 day $(0.33 \pm 0.20)$ (Figure $5 \mathbf{A}$, right). In accordance with this observation, western blot analysis indicated that APP $(\sim 100 \mathrm{kDa})$ was decreased after PBBI (Figure 5B, left). Here, APP protein levels fell precipitously at 3 day $(0.13 \pm 0.02)$ and 7 day $(0.05 \pm 0.03)$ after PBBI compared to Sham-operated controls (Figure 5B, right). APP loss was also detected per the use of the N-terminal antibody, 22C11 (data not shown). Secreted $\mathrm{APP}-\alpha / \beta$, C-terminal fragments, and $\mathrm{A} \beta$ peptides are main products of BACE1 and PSEN1/2 APP degradation. Thus, levels of these peptides was tested in brain tissue lysates. Cleavage products, such as secreted $\mathrm{APP}-\alpha / \beta$ and $\mathrm{C}$-terminal fragments (CTFs), were detectable in this study; but the resolution was poor (data not shown). However, $A \beta-40$ content increased after PBBI $(0.43 \pm 0.05 \mathrm{ng} / \mathrm{mL})$ relative to Sham-operated controls $(0.30 \pm 0.06 \mathrm{ng} / \mathrm{mL})$ at 7 day (Figure 5C, left). Surprisingly, A $\beta$ 42 decreased, albeit marginally, after PBBI $(0.05 \pm 0.005 \mathrm{ng} / \mathrm{mL})$ compared to Sham-operated $(0.07 \pm 0.003 \mathrm{ng} / \mathrm{mL})$ at this same time-point (Figure 5C, center). Fold change transformation of the peptide data further illustrates the increase in $\mathrm{A} \beta-40$ versus $\mathrm{A} \beta-42$ at 7 day after PBBI (Figure 5C, right). Here, the peptide ratio doubled $(9.1 \pm 1.1 \mathrm{AU})$ compared to Sham-operated controls (4.5 $\pm 1.0 \mathrm{AU})$.

\section{DISCUSSION}

Analysis of miRNAs and their proposed targets can shed light upon TBI - induced processes that are associated with neurodegeneration. MiRNA array analysis, systems biology, and quantitation of downstream mRNA targets (inferred from systems biology analysis) indicated that a subset of miRNAs affected by PBBI were specific for each time-point and associated with inflammation or neurodegeneration, well-known aspects of TBI progression. Further, several miRNAs were specifically associated with mRNAs within the APP-processing pathway, particularly BACE1, a key APP degrading enzyme.

\section{PBBI Leads to Temporally Specific miRNA Dysregulation Associated With Inflammation and Neurodegeneration}

Our earlier work indicated that miRNAs affected by PBBI were associated with inflammation (Johnson et al., 2017). It is likely that miRNAs are correlated with, and perhaps involved in, a myriad of deleterious processes that occur throughout TBI progression. The data presented herein collectively indicates that PBBI leads to transcriptional dysregulation of more than 60 miRNAs, most of which occurred 7 day after PBBI. In comparison, fluid percussion injury (FPI) has been reported to affect a set of 24-27 miRNAs 1-3 days post-injury (Lei et al., 2009). Ten miRNAs were consistently dysregulated in hippocampal lysates collected $1 \mathrm{~h}-7$ day after controlled cortical impact (CCI), which was defined after comparison to a Shamoperated control collected at a single time-point after injury (Liu et al., 2014a).

Several of the miRNAs affected by PBBI in this study have been reported to be involved in inflammation as well as neurodegeneration. MiR-667 and miR-335 were both decreased 3-7 days after PBBI. MiR-667 is a transcriptional repressor of catechol-O-methyltransferase (COMT) (Segall et al., 2015), a gene that is upregulated in response to trauma-induced microglial activation (Redell and Dash, 2007). MiR-335 targets insulin-like growth factor receptor (IGF-R) (Gong et al., 2014). The IGF-1/IGF-R pathway is crucial to cellular metabolism affected by TBI and the ligand, IGF-1, is increased in damaged cortical and hippocampal regions 3-7 day after PBBI (Madathil and Saatman, 2015; Madathil et al., 2017). It is possible that this observation is relevant to neurogenesis during attempted repair (Madathil et al., 2013). However, the interaction between miRNA and gene targets that overlap processes, such as inflammation, neurodegeneration, and neurogenesis require further study within this model. PBBI-induced upregulation of miR-155 and 
A

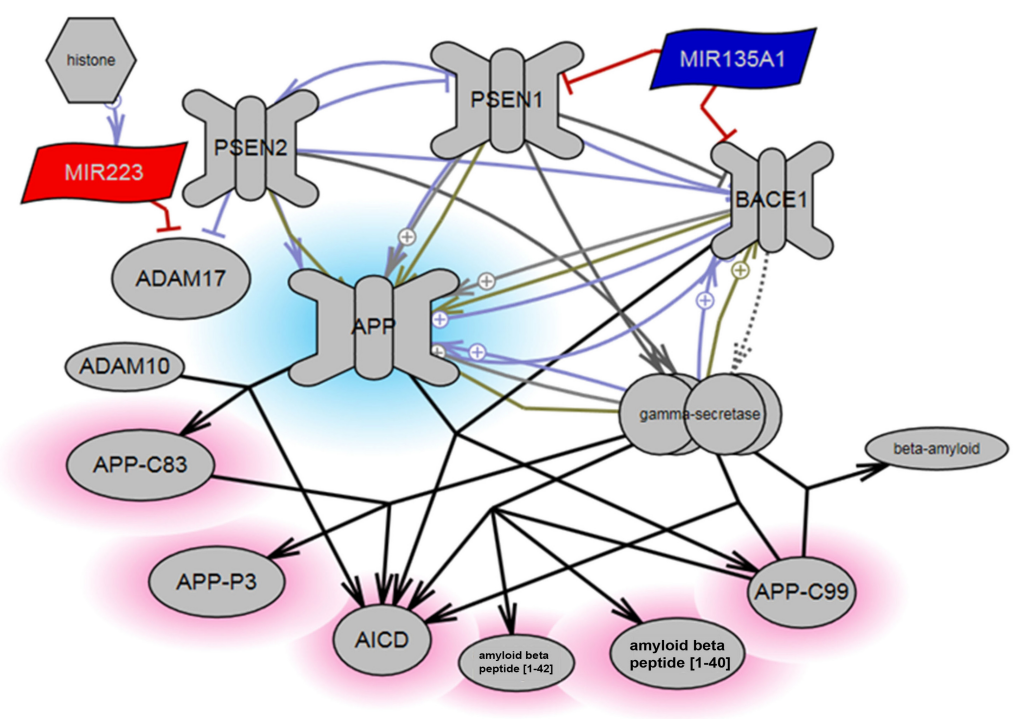

B

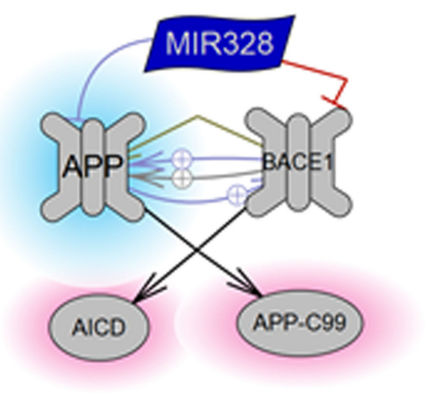

C

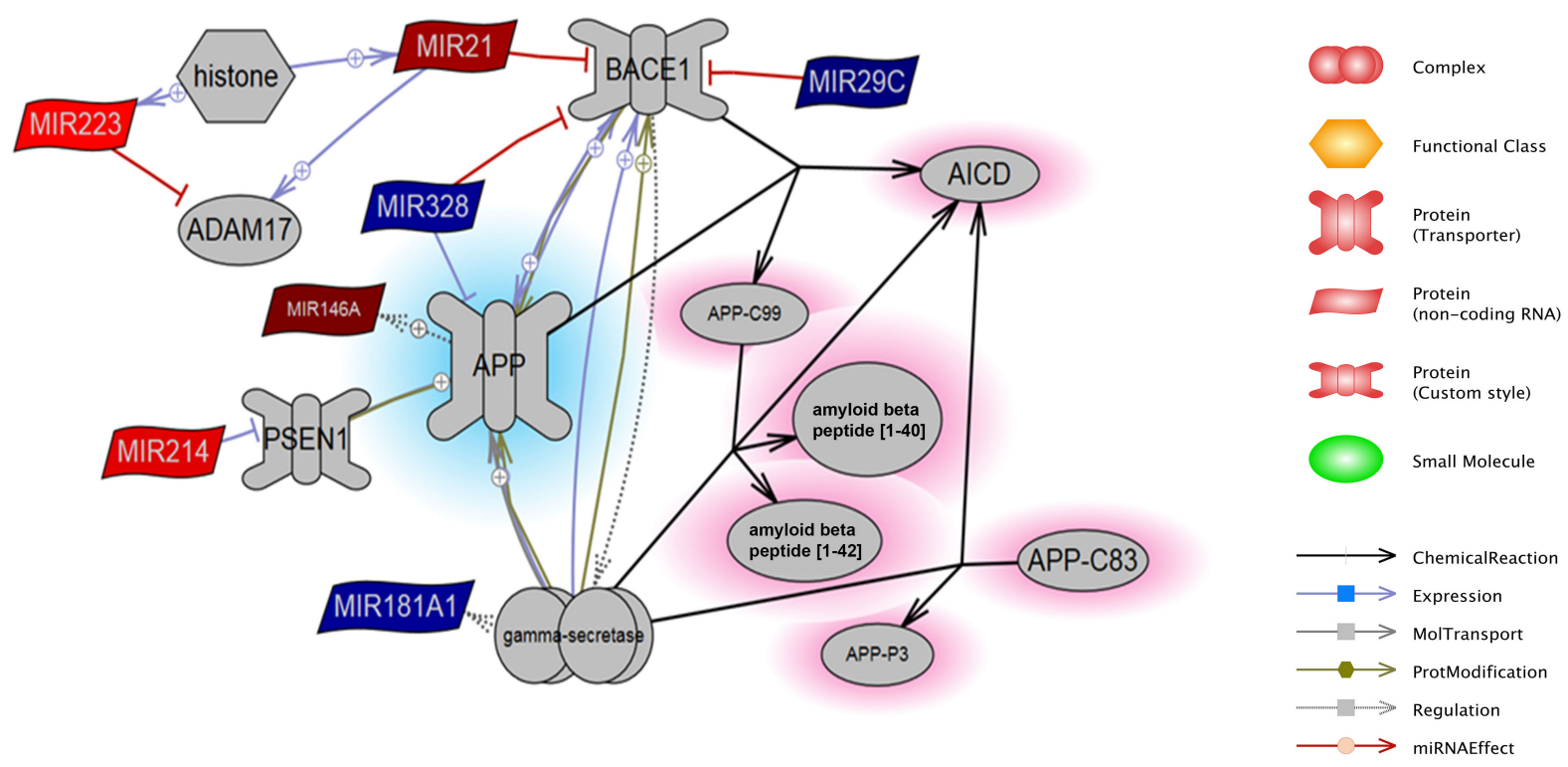

FIGURE 3 | MiRNA Targets of the APP Processing Pathway. The constructed pathways containing miRNAs derived from brain tissues collected at (A) 1 day, (B) 3 day, and (C) 7 day after PBBI are indicated with respective relationships to proteins involved in APP processing. MiRNAs that were decreased (blue) or increased (red) after PBBI compared to Sham-operated controls as derived from microarray results are shown with relationships relevant to APP (blue highlight) and its peptides (red highlight). BACE1 - $\beta$-site amyloid precursor protein cleaving enzyme 1, the gene that encode $\beta$-secretase; PSEN1/2 - presenilin 1 or 2; APP amyloid precursor protein, AICD - APP C-terminal fragment produced by $\gamma$-secretase cleavage; APP-C99 - APP C-terminal fragment produced by $\beta$-secretase encoded by BACE1; APP-C83 - APP C-terminal fragment $\alpha$-secretase cleavage; APP-P3 - fragment of APP-C83 produced by $\gamma$-secretase cleavage. The size of the molecules within images are not to scale with molecular weight or tertiary structure.

-223 may occur as a consequence of microglial activation (Thounaojam et al., 2013; Lee et al., 2018) as well as posttraumatic mitochondrial injury, a novel therapeutic target for TBI (Wang et al., 2015; Harmon et al., 2017).

MiR-21 is one of the most well studied suppressors of gene expression in cellular biology and is considered a master regulator of cell growth and proliferation in response to post-traumatic apoptosis (Krichevsky and Gabriely, 2009). For instance, subacute upregulation of miR-21 reduces neuronal cell death and blood brain barrier damage, indicating that it may have a due role in cellular damage as well as repair after TBI that is dependent upon the time frame, brain region, or cell type affected (Ge et al., 2014, 2015; Han et al., 2014). Upregulation of miR21 was previously found to be associated with pro-inflammatory 
A Levels of miRNA Proposed to be Downregulated after PBBI.

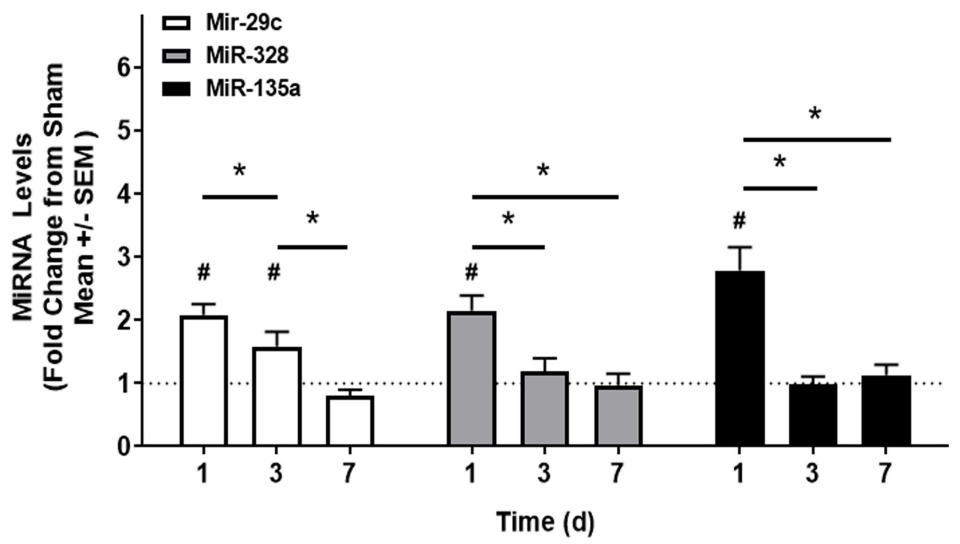

B Levels of miRNA Proposed to be Upregulated after PBBI.

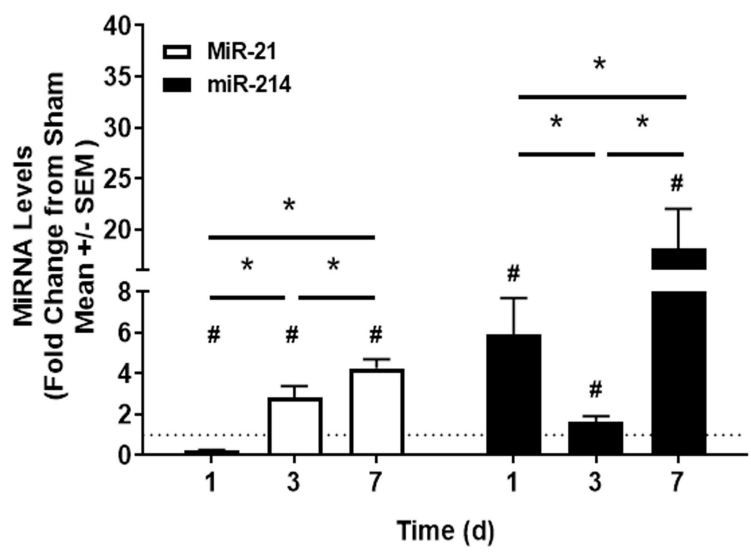

c Levels of mRNAs affected by PBBI.

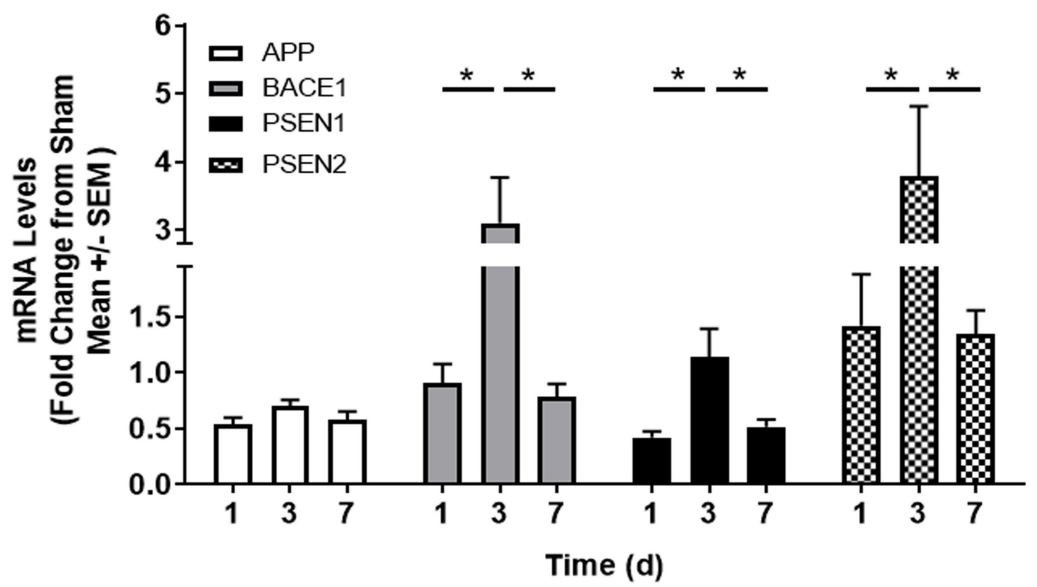

FIGURE 4 | Quantitation of miRNAs and mRNAs Associated with the APP Processing Pathway. Q-PCR of miRNA proposed to be deregulated after PBBI. (A) Levels of miRNA proposed to be downregulated after PBBI. MiR-29c (white bars), miR-328 (gray bars), and miR-135a (black bars) are shown. (B) Levels of miRNA proposed to be upregulated after PBBI. MiR-21 (white bars) and miR-214 (black bars) are displayed. (C) Levels of mRNAs affected by PBBI. APP (white bars), BACE1 (gray bars), PSEN1 (black bars), and PSEN2 (checkered bars) are indicated. MiRNA and mRNA Ct levels were subtracted from Ct values detected for mammU6-RNA or $\beta$-actin, respectively. Data is displayed as the fold change (mean \pm SEM) normalized Sham-operated control (dotted line $=1$ ) indicating time after injury ( $x$-axis) compared to quantitation ( $y$-axis). Significant values are defined with an asterisk (\#, $p \leq 0.05$, two-tailed $t$-test, PBBI vs. Sham at each time point; ${ }^{*}, p \leq 0.05$, PBBI cohorts). 


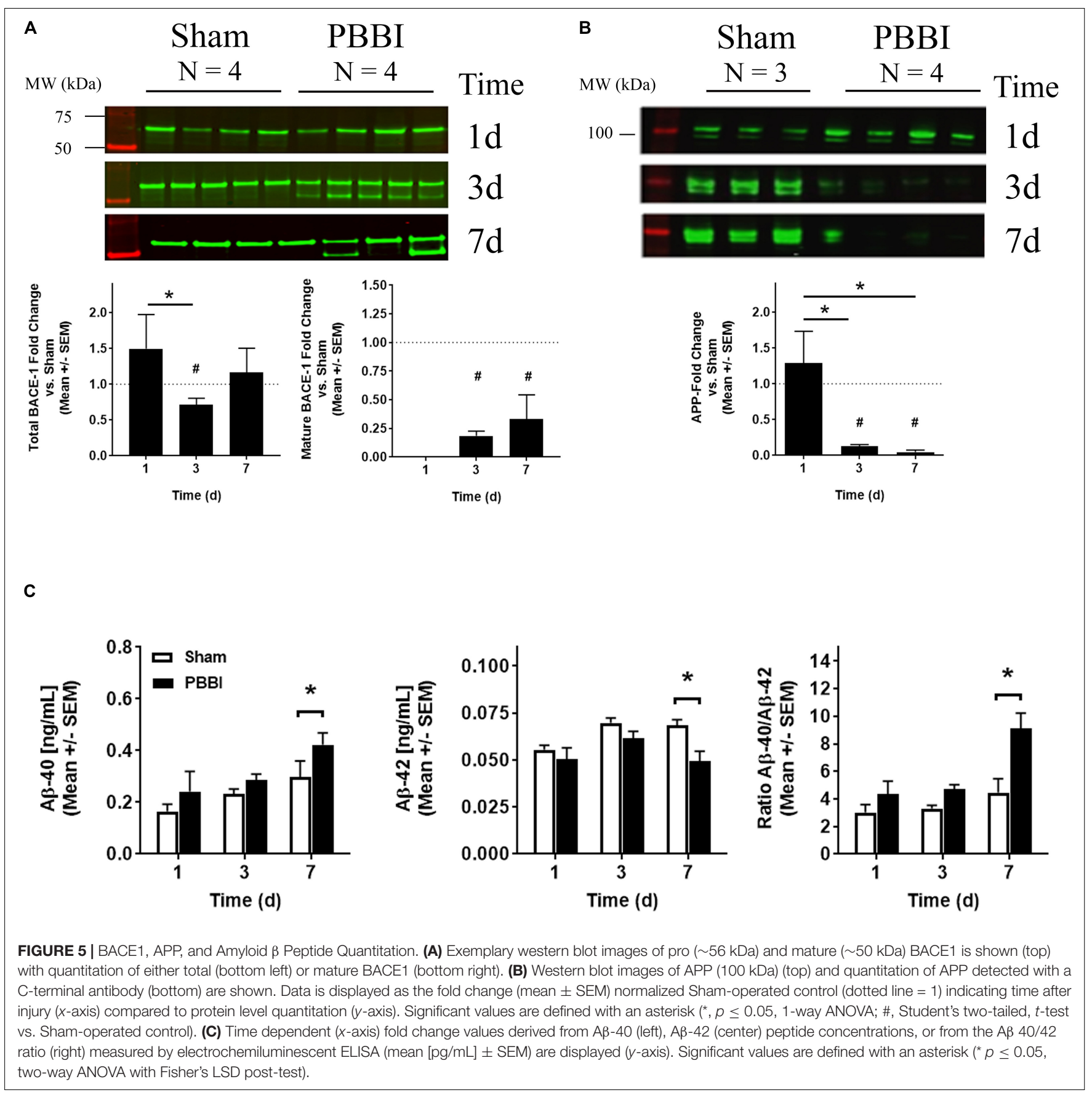

cytokine upregulation in the PBBI and CCI models (Redell et al., 2011; Johnson et al., 2017). The relative influence that miR-21 may have in the presence of other miRNAs at various time-points is not known, upregulation in this study infers that miR-21 may have utility as a key regulator, or hub, within multiple TBI models.

Of note, this study used a database that annotates all interactions for "mmu-miR-21\#" (the $-3 p$ strand) and "hsamiR-21" (the $-5 \mathrm{p}$ strand) into a single entry for miR-21. Although both sequences have been shown to be dysregulated in TBI models and we are aware that miR-21-3p and miR21-5p may have opposing functions (Ge et al., 2019), we have chosen to validate miR-21-5p due to evidence of its upregulation in our previous study of the PBBI model, specifically (Johnson et al., 2017). The relative impact of $3 p$ versus $-5 p$ sequences are considered in the context coexpressed biomarkers (Choo et al., 2014) or for therapeutic strategies involving inflammation. These topics are key, yet potentially broad, features of TBI progression that offer rationale to understand interactions and roles involving miRNA within concurrent and future studies. Instead, these data have also uncovered potentially unified processes associated with protein degradation. 


\section{PBBI-Induced MiRNA Dysregulation Is Associated With BACE1 Upregulation and APP Loss Relevant to Widespread Degradation}

Associative analysis of miRNAs is highly informative in regards to known events in TBI progression. Arrays coupled to pathway analysis may serve as predicates to further refine hypotheses and conduct secondary assessment. A minor caveat of all genetics studies and translation to protein levels is that the absolute fold change data derived from arrays occasionally varies from that of individual qPCR. This slight change is expected due to differences in RNA isolation and the limits of detection of platforms used, as well as biological variance inherent to animal models. A common, yet underreported source of variance exists across different qPCR platforms such as open array and single tube or 96 well (Mestdagh et al., 2014; Farr et al., 2015; Martin-Alonso et al., 2018). Low abundant transcripts introduce a higher variability on high throughput platforms, even though preamplification steps are introduced. In PBBI, an acceptable range of variance is common among genes or proteins as shown in prior reports which is associated with ipsilateral lesion volume and tissue loss in any single cohort (Mondello et al., 2016). However, widespread protein and brain tissue degradation is a consistent feature of open skull, severe TBI models per observation of apoptosis (Brophy et al., 2009; Cartagena et al., 2013), as well as axonal fiber and cellular degeneration (Brophy et al., 2009; Shear et al., 2009; Gajavelli et al., 2015). A novel aspect of this model is presented by this study, which found that miRNAs affected by PBBI over time collectively mapped to APP processing, a key feature of neurodegeneration (Roberts et al., 1994; Nguyen, 2019; Shin et al., 2019), that overlaps the timeframe of widespread degradation in this model.

Although APP processing is dominated by nonamyloidogenic alpha $(\alpha)$-secretase cleavage pathway involving ADAM family enzymes (Parvathy et al., 1999), the amyloidogenic mechanism of APP degradation involves two key enzymes, $\beta$-secretase (BACE1) and the gamma $(\gamma)$-secretase complex composed of PSEN1/2 (Vassar et al., 1999; Zhang et al., 2001; Chow et al., 2010) and other proteins which can be activated under pathological conditions (Zhang et al., 2011). In this case, APP is cleaved by $\beta$-secretase to release sAPP $\beta$ and CTF99, then the $\gamma$-secretase complex, cleaves CTF99 to generate $\mathrm{A} \beta-40 /-42$ (Cole and Vassar, 2008). Our lab previously indicated that APP loss occurs during subacute PBBI (Cartagena et al., 2016). Therefore, the results presented herein suggest that miRNAs may be coordinated with APP cleavage through enzymes during acute-subacute TBI progression.

This study showed miR-21 or -214 elevation coupled with miRNA-328 or -135A suppression were associated with BACE1 and PSEN2 modulation, which is in accordance with former studies detailing suppression of BACE1 by miR-135A, miR328, and miR-29c in cell cultures (Zong et al., 2011; Liu et al., 2014b) and transgenic mouse models of AD (Boissonneault et al., 2009). In post-mortem brain tissues derived from patients diagnosed with non-familial AD, miR29c or miR-328 were inversely proportional to BACE1 gene levels (Hebert et al., 2008; Shioya et al., 2010; Lei et al., 2015). Increased levels of miR-223 inversely related to ADAM17 were observed. Yet, no miRNAs directly associated with ADAM10, and there were no relationships observed 3 day after PBBI. Loss of two, but upregulation of one, miRNA that each have negative relationships with BACE1 coupled with potential suppression of ADAM17 and the lack of a role for ADAM10, infer coordination of miRNA and mRNA events within injured brain tissue in line with a net gain of BACE1 as a key factor. Additional evaluation is on-going to determine the relative influence of ADAM10, and ADAM17 compared to BACE1 in this model.

Delayed upregulation and cleavage to the mature form of BACE1 during APP loss infers that injured brain tissue undergo proteolysis or remodeling throughout subacute time-frames. The relative increase in $A \beta-40$, compared to near ablation of full length APP, was somewhat small. Therefore, the role of BACE1 may be more robust than that of $\gamma$-secretase in this model. This observation is fitting for several reasons. First, BACE1 transcripts and $\beta$-secretase activity are upregulated in damaged neurons and activated astrocytes as a consequence of acutesubacute TBI (Blasko et al., 2004; Yu et al., 2012). BACE1 cleaves a variety of substrates (Hemming et al., 2009) and is associated with decreased dendritic spine integrity (Savonenko et al., 2008) and axonal blebbing (Hitt et al., 2012; Hu et al., 2015), which is due to an increase in the number of APP positive neuronal terminals (Tran et al., 2011) after brain trauma. This feature has been detected in the PBBI model upon detection of increased immunoreactivity from a C-terminal antibody that recognizes both APP and A $\beta$ peptides (Lu et al., 2016). A large swath of the ipsilateral brain is damaged by PBBI. Thus, APP positive cells likely contain a mixture of intact as well as cleaved peptides (Burton et al., 2008; Wahrle et al., 2008; Muresan et al., 2009). The PBBI model does not replicate amyloidosis (plaques) per se, but it does lead to drastic fragmentation of many neuronal proteins (DeDominicis et al., 2018), inclusive of APP as previously mentioned, in addition to tissue loss in a manner that is much more drastic than CCI or FPI (Mountney et al., 2016).

Second, APP degradation may occur via multiple enzymatic pathways (Abrahamson et al., 2006; Ikonomovic et al., 2017) although it is mostly widely studied in the context of degenerative A $\beta$ plaques (Hartig et al., 2010; Gouras et al., 2015). It is possible that PBBI leads to widespread APP fragmentation associated with miRNA dysregulation and BACE1, prior to redistribution or seeding of APP as seen in this model at later time points. This aspect of brain trauma may be similar to the observation that APP and its fragments are detectable in the soma, as well as dendritic and axonal terminals of injured cells (DeBoer et al., 2014; Niederst et al., 2015). Thus, the observed shifts in BACE1 and APP associated with this miRNA profile is a reflection of widespread damage to the brain tissue.

Lastly, the later steps in APP processing rely upon PSEN1/2 variants within the active $\gamma$-secretase complex may be responsible for extensive and sustained $A \beta-40 / 42$ peptide generation and seeding after action upon APP by BACE1. APP and its peptides 
are often studied in TBI rodent models that carry the mutated PSEN transgenes (Cheng et al., 2019) in an effort to show direct relationships to early onset dementia (Gotz et al., 2018). These mutations are rare and indicate that analysis in wild type models, as in this study, are increasingly important. Notably, A $\beta-40$ is the dominant peptide in brain trauma as well as sporadic (non-transgenic) AD in rat models (Shin et al., 1997). The negative relationship between miR-135A (decreased at 1 day) or miR-214 (increased, at 7 day) and either PSEN1 were sparse compared to the relationships shown for BACE1 over time. Further, the other $\gamma$-secretase complex proteins (e.g., nicastrin) (Kimberly et al., 2003) were not associated with the miRNAs expressed in PBBI damaged tissues found in this study. As such, $\mathrm{A} \beta-40$ may be the expected dominant form of APP peptide produced in a TBI model.

A potential caveat of this study is that resolution of $\operatorname{sAPP} \alpha$ or sAPP $\beta$ was poor in this model per the techniques used. Future work will explore use of alternative methods. Although APP degradation is well studied in cell culture models, post-mortem human brain, or transgenic mice in the context of $\mathrm{AD}$, it remains relatively understudied brain tissues derived from wild-type rat models subjected to the most severe, survivable hemorrhagic model of TBI. It is also possible that the molar ratio of $\operatorname{sAP} \alpha$ or sAPP $\beta$ may be too low for detection by current techniques in this context. Assessment of these fragments is on-going for this model. Overall, miRNA associated BACE1 upregulation may be the key initial step in wholesale APP degradation after TBI.

\section{CONCLUSION}

A subset of miRNAs found in this study may be putative to TBIinduced inflammation and neurodegeneration. These miRNAs, as well as BACE1, within the APP pathway may serve as novel biomarkers of degradation or reduced neuronal integrity in brain tissues. More importantly, this study is the first to show that coordinated miRNA dysregulation, elevation of BACE1, and post-transcriptional APP loss co-occur in a non-transgenic rodent model of severe TBI. The observations presented are associative, yet use of arrays and pathway analysis are useful in augmenting hypotheses to study the secondary effects of TBI that lead to widespread cell and tissue loss defined by discreet, rather than broad, analysis. MiRNAs regulate broad networks of genes. Thus, identifying those which are dysregulated as a consequence of TBI offer a means to elucidate molecular mechanisms, or hubs, that underlie neurodegeneration and may serve as viable therapeutic targets. Refinement of interaction mapping and connectivity displays per extensive knowledge of

\section{REFERENCES}

Abrahamson, E. E., Ikonomovic, M. D., Ciallella, J. R., Hope, C. E., Paljug, W. R., Isanski, B. A., et al. (2006). Caspase inhibition therapy abolishes brain traumainduced increases in A beta peptide: implications for clinical outcome. Exp. Neurol. 197, 437-450. doi: 10.1016/j.expneurol.2005.10.011

Blasko, I., Beer, R., Bigl, M., Apelt, J., Franz, G., Rudzki, D., et al. (2004). Experimental traumatic brain injury in rats stimulates the expression,
APP processing and studies to determine direct roles of these miRNAs, inclusive of in vivo interactions in the PBBI model, are in progress.

\section{DATA AVAILABILITY STATEMENT}

All datasets presented in this study are included in the article/Supplementary Material.

\section{ETHICS STATEMENT}

The experimental procedures were approved by the WRAIR Animal Care and Use Committee. Research was conducted in compliance with the Animal Welfare Act and other federal statutes and regulations relating to animals and experiments involving animals, and adheres to principles stated in the Guide for the Care and Use of Laboratory Animals, NRC Publication, 2011 edition.

\section{AUTHOR CONTRIBUTIONS}

BT, DJ, and AMB conceived the experimental design and conducted the sample preparation and data analysis. All authors prepared the manuscript.

\section{FUNDING}

This research was funded by Combat Casualty Care Research Program.

\section{ACKNOWLEDGMENTS}

The authors thank Ms. Roxanne Ashworth and Johns Hopkins University, Ms. Xiaofang Yang, Ms. Shonnette F. Grant, Ms. Barbie Ann Stephen, Ms. Brittany N. Abbatiello, Ms. Savannah R. Barannikov, and Mr. Justin Sun for their technical expertise.

\section{SUPPLEMENTARY MATERIAL}

The Supplementary Material for this article can be found online at: https://www.frontiersin.org/articles/10.3389/fnins. 2020.00915/full\#supplementary-material

production and activity of Alzheimer's disease beta-secretase (BACE-1). J. Neural. Transm. 111, 523-536. doi: 10.1007/s00702-003-0095-6

Boissonneault, V., Plante, I., Rivest, S., and Provost, P. (2009). MicroRNA-298 and microRNA-328 regulate expression of mouse beta-amyloid precursor protein-converting enzyme 1. J. Biol. Chem. 284, 1971-1981. doi: 10.1074/jbc. M807530200

Boone, D. K., Weisz, H. A., Bi, M., Falduto, M. T., Torres, K. E. O., Willey, H. E., et al. (2017). Evidence linking microRNA suppression of essential prosurvival 
genes with hippocampal cell death after traumatic brain injury. Sci. Rep. 7:6645.

Boutte, A. M., Deng-Bryant, Y., Johnson, D., Tortella, F. C., Dave, J. R., Shear, D. A., et al. (2016). Serum glial fibrillary acidic protein predicts tissue glial fibrillary acidic protein break-down products and therapeutic efficacy after penetrating ballistic-like brain injury. J. Neurotrauma 33, 147-156. doi: 10.1089/neu.2014. 3672

Boutte, A. M., Hook, V., Thangavelu, B., Sarkis, G. A., Abbatiello, B. N., Hook, G., et al. (2020). Penetrating traumatic brain injury triggers dysregulation of cathepsin B protein levels independent of cysteine protease activity in brain and cerebral spinal fluid. J. Neurotrauma 2020, 1574-1586. doi: 10.1089/neu.2019. 6537

Boutte, A. M., Thangavelu, B., LaValle, C. R., Nemes, J., Gilsdorf, J., Shear, D. A., et al. (2019). Brain-related proteins as serum biomarkers of acute, subconcussive blast overpressure exposure: a cohort study of military personnel. PLoS One 14:e0221036. doi: 10.1371/journal.pone.0221036

Brophy, G. M., Pineda, J. A., Papa, L., Lewis, S. B., Valadka, A. B., Hannay, H. J., et al. (2009). alphaII-Spectrin breakdown product cerebrospinal fluid exposure metrics suggest differences in cellular injury mechanisms after severe traumatic brain injury. J. Neurotrauma 26, 471-479. doi: 10.1089/neu.2008.0657

Burton, C. R., Meredith, J. E., Barten, D. M., Goldstein, M. E., Krause, C. M., Kieras, C. J., et al. (2008). The amyloid-beta rise and gamma-secretase inhibitor potency depend on the level of substrate expression. J. Biol. Chem. 283, 22992-23003. doi: 10.1074/jbc.M804175200

Cartagena, C. M., Mountney, A., Hwang, H., Swiercz, A., Rammelkamp, Z., Boutte, A. M., et al. (2016). Subacute changes in cleavage processing of amyloid precursor protein and tau following penetrating traumatic brain injury. PLoS One 11:e0158576. doi: 10.1371/journal.pone.0158576

Cartagena, C. M., Schmid, K. E., Phillips, K. L., Tortella, F. C., and Dave, J. R. (2013). Changes in apoptotic mechanisms following penetrating ballistic-like brain injury. J. Mol. Neurosci. 49, 301-311. doi: 10.1007/s12031-012-9828-z

Che, H., Yan, Y., Kang, X. H., Guo, F., Yan, M. L., Liu, H. L., et al. (2017). MicroRNA-27a promotes inefficient lysosomal clearance in the hippocampi of rats following chronic brain hypoperfusion. Mol. Neurobiol. 54, 2595-2610. doi: 10.1007/s12035-016-9856-8

Cheng, W. H., Martens, K. M., Bashir, A., Cheung, H., Stukas, S., Gibbs, E., et al. (2019). CHIMERA repetitive mild traumatic brain injury induces chronic behavioural and neuropathological phenotypes in wild-type and APP/PS1 mice. Alzheimers Res. Ther. 11:6. doi: 10.1186/s13195-018-0461-0

Choo, K. B., Soon, Y. L., Nguyen, P. N., Hiew, M. S., and Huang, C. J. (2014). MicroRNA-5p and $-3 \mathrm{p}$ co-expression and cross-targeting in colon cancer cells. J. Biomed. Sci. 21:95. doi: 10.1186/s12929-014-0095-x

Chow, V. W., Mattson, M. P., Wong, P. C., and Gleichmann, M. (2010). An overview of APP processing enzymes and products. Neuromol. Med. 12, 1-12. doi: 10.1007/s12017-009-8104-z

Cole, S. L., and Vassar, R. (2008). The role of amyloid precursor protein processing by BACE1, the beta-secretase, in Alzheimer disease pathophysiology. J. Biol. Chem. 283, 29621-29625. doi: 10.1074/jbc.R800015200

Cunningham, T. L., Cartagena, C. M., Lu, X. C., Konopko, M., Dave, J. R., Tortella, F. C., et al. (2014). Correlations between blood-brain barrier disruption and neuroinflammation in an experimental model of penetrating ballistic-like brain injury. J. Neurotrauma 31, 505-514. doi: 10.1089/neu.2013.2965

Cuthbert, J. P., Harrison-Felix, C., Corrigan, J. D., Kreider, S., Bell, J. M., Coronado, V. G., et al. (2015). Epidemiology of adults receiving acute inpatient rehabilitation for a primary diagnosis of traumatic brain injury in the United States. J. Head Trauma Rehabil. 30, 122-135. doi: 10.1097/Htr. 0000000000000012

DeBoer, S. R., Dolios, G., Wang, R., and Sisodia, S. S. (2014). Differential release of beta-amyloid from dendrite- versus axon-targeted APP. J. Neurosci. 34, 12313-12327. doi: 10.1523/JNEUROSCI.2255-14.2014

DeDominicis, K. E., Hwang, H., Cartagena, C. M., Shear, D. A., and Boutte, A. M. (2018). Cerebrospinal fluid biomarkers are associated with glial fibrillary acidic protein and alpha II-spectrin breakdown products in brain tissues following penetrating ballistic-like brain injury in rats. Front. Neurol. 9:490. doi: 10.3389/ fneur.2018.00490

Eacker, S. M., Dawson, T. M., and Dawson, V. L. (2009). Understanding microRNAs in neurodegeneration. Nat. Rev. Neurosci. 10, 837-841. doi: 10. $1038 /$ nrn2726
Eaton, S. L., Roche, S. L., Hurtado, M. L., Oldknow, K. J., Farquharson, C., Gillingwater, T. H., et al. (2013). Total protein analysis as a reliable loading control for quantitative fluorescent western blotting. PLoS One 8:e072457. doi: 10.1371/journal.pone.0072457

Fabian, M. R., Sonenberg, N., and Filipowicz, W. (2010). Regulation of mRNA Translation and stability by microRNAs. Annu. Rev. Biochem. 79, 351-379. doi: 10.1146/annurev-biochem-060308-103103

Farr, R. J., Januszewski, A. S., Joglekar, M. V., Liang, H., McAulley, A. K., Hewitt, A. W., et al. (2015). A comparative analysis of high-throughput platforms for validation of a circulating microRNA signature in diabetic retinopathy. Sci. Rep. 5:10375. doi: 10.1038/srep10375

Franz, C. K., Joshi, D., Daley, E. L., Grant, R. A., Dalamagkas, K., Leung, A., et al. (2019). Impact of traumatic brain injury on amyotrophic lateral sclerosis: from bedside to bench. J. Neurophysiol. 122, 1174-1185. doi: 10.1152/jn.00572.2018

Friedemann-Sanchez, G., Sayer, N. A., and Pickett, T. (2008). Provider perspectives on rehabilitation of patients with polytrauma. Arch. Phys. Med. Rehabil. 89, 171-178. doi: 10.1016/j.apmr.2007.10.017

Gajavelli, S., Kentaro, S., Diaz, J., Yokobori, S., Spurlock, M., Diaz, D., et al. (2015). Glucose and oxygen metabolism after penetrating ballistic-like brain injury. J. Cereb. Blood Flow Metab. 35, 773-780. doi: 10.1038/jcbfm.2014.243

Gardner, R. C., Byers, A. L., Barnes, D. E., Li, Y., Boscardin, J., and Yaffe, K. (2018). Mild TBI and risk of Parkinson disease: a chronic effects of neurotrauma consortium study. Neurology 90:e01771-79. doi: 10.1212/WNL. 0000000000005522

Ge, X., Han, Z., Chen, F., Wang, H., Zhang, B., Jiang, R., et al. (2015). MiR-21 alleviates secondary blood-brain barrier damage after traumatic brain injury in rats. Brain Res. 1603, 150-157. doi: 10.1016/j.brainres.2015.01.009

Ge, X., Li, W., Huang, S., Yin, Z., Yang, M., Han, Z., et al. (2019). Increased miR21-3p in injured brain microvascular endothelial cells after traumatic brain injury aggravates blood-brain barrier damage by promoting cellular apoptosis and inflammation through targeting MAT2B. J. Neurotrauma 36, 1291-1305. doi: 10.1089/neu.2018.5728

Ge, X. T., Lei, P., Wang, H. C., Zhang, A. L., Han, Z. L., Chen, X., et al. (2014). miR-21 improves the neurological outcome after traumatic brain injury in rats. Sci. Rep. 4:6718. doi: 10.1038/srep06718

Goldstein, L., and Diaz-Arrastia, R. (2018). Traumatic brain injury and risk of suicide. JAMA 320, 554-556. doi: 10.1001/jama.2018.10825

Gong, M., Ma, J., Guillemette, R., Zhou, M., Yang, Y., Yang, Y., et al. (2014). miR335 inhibits small cell lung cancer bone metastases via IGF-IR and RANKL pathways. Mol. Cancer Res. 12, 101-110. doi: 10.1158/1541-7786.MCR-130136

Gotz, J., Bodea, L. G., and Goedert, M. (2018). Rodent models for Alzheimer disease. Nat. Rev. Neurosci. 19, 583-598. doi: 10.1038/s41583-018-0054-8

Gouras, G. K., Olsson, T. T., and Hansson, O. (2015). beta-Amyloid peptides and amyloid plaques in Alzheimer's disease. Neurotherapeutics 12, 3-11. doi: 10.1007/s13311-014-0313-y

Grigorenko, E. V., Ortenberg, E., Hurley, J., Bond, A., and Munnelly, K. (2011). miRNA profiling on high-throughput OpenArray system. Methods Mol. Biol. 676, 101-110. doi: 10.1007/978-1-60761-863-8_8

Han, Z., Chen, F., Ge, X., Tan, J., Lei, P., and Zhang, J. (2014). miR-21 alleviated apoptosis of cortical neurons through promoting PTEN-Akt signaling pathway in vitro after experimental traumatic brain injury. Brain Res. 1582, 12-20. doi: 10.1016/j.brainres.2014.07.045

Harmon, J. L., Gibbs, W. S., Whitaker, R. M., Schnellmann, R. G., and Adkins, D. L. (2017). Striatal mitochondrial disruption following severe traumatic brain injury. J. Neurotrauma 34, 487-494. doi: 10.1089/neu.2015.4395

Hartig, W., Goldhammer, S., Bauer, U., Wegner, F., Wirths, O., Bayer, T. A., et al. (2010). Concomitant detection of beta-amyloid peptides with $\mathrm{N}$-terminal truncation and different C-terminal endings in cortical plaques from cases with Alzheimer's disease, senile monkeys and triple transgenic mice. J. Chem. Neuroanat. 40, 82-92. doi: 10.1016/j.jchemneu.2010.03.006

He, Z. H., Guo, J. L., McBride, J. D., Narasimhan, S., Kim, H., Changolkar, L., et al. (2018). Amyloid-beta plaques enhance Alzheimer's brain tau-seeded pathologies by facilitating neuritic plaque tau aggregation. Nat. Med. 24, 29-38. doi: $10.1038 / \mathrm{nm} .4443$

Hebert, S. S., Horre, K., Nicolai, L., Papadopoulou, A. S., Mandemakers, W., Silahtaroglu, A. N., et al. (2008). Loss of microRNA cluster miR-29a/b-1 in sporadic Alzheimer's disease correlates with increased BACE1/beta-secretase 
expression. Proc. Natl. Acad. Sci. U.S.A. 105, 6415-6420. doi: 10.1073/pnas. 0710263105

Hemming, M. L., Elias, J. E., Gygi, S. P., and Selkoe, D. J. (2009). Identification of beta-Secretase (BACE1) substrates using quantitative proteomics. PLoS One 4:8477. doi: 10.1371/journal.pone.0008477

Hitt, B., Riordan, S. M., Kukreja, L., Eimer, W. A., Rajapaksha, T. W., and Vassar, R. (2012). beta-Site amyloid precursor protein (APP)-cleaving enzyme 1 (BACE1)deficient mice exhibit a close homolog of L1 (CHL1) loss-of-function phenotype involving axon guidance defects. J. Biol. Chem. 287, 38408-38425. doi: 10.1074/ jbc.M112.415505

Hu, X. Y., Hu, J. X., Dai, L., Trapp, B., and Yan, R. Q. (2015). Axonal and schwann cell BACE1 Is equally required for remyelination of peripheral nerves. J. Neurosci. 35, 3806-3814. doi: 10.1523/Jneurosci.5207-14.2015

Ikonomovic, M. D., Mi, Z. P., and Abrahamson, E. E. (2017). Disordered APP metabolism and neurovasculature in trauma and aging: combined risks for chronic neurodegenerative disorders. Age. Res. Rev. 34, 51-63. doi: 10.1016/j. arr.2016.11.003

Johnson, D., Cartagena, C. M., Tortella, F. C., Dave, J. R., Schmid, K. E., and Boutte, A. M. (2017). Acute and subacute microRNA dysregulation is associated with cytokine responses in the rodent model of penetrating ballistic-like brain injury. J. Trauma Acute Care Surg. 83(1 Suppl. 1), S145-S149. doi: 10.1097/TA. 0000000000001475

Karnati, H. K., Panigrahi, M. K., Gutti, R. K., Greig, N. H., and Tamargo, I. A. (2015). miRNAs: key players in neurodegenerative disorders and epilepsy. J. Alzheimers Dis. 48, 563-580. doi: 10.3233/JAD- 150395

Khoshnam, S. E., Winlow, W., and Farzaneh, M. (2017). The interplay of MicroRNAs in the inflammatory mechanisms following ischemic stroke. J. Neuropathol. Exp. Neurol. 76, 548-561. doi: 10.1093/jnen/nlx036

Kimberly, W. T., LaVoie, M. J., Ostaszewski, B. L., Ye, W., Wolfe, M. S., and Selkoe, D. J. (2003). Gamma-secretase is a membrane protein complex comprised of presenilin, nicastrin, Aph-1, and Pen-2. Proc. Natl. Acad. Sci. U.S.A. 100, 6382-6387. doi: 10.1073/pnas. 1037392100

Krichevsky, A. M., and Gabriely, G. (2009). miR-21: a small multi-faceted RNA. J. Cell Mol. Med. 13, 39-53. doi: 10.1111/j.1582-4934.2008.00556.x

Langlois, J. A., Rutland-Brown, W., and Thomas, K. E. (2005). The incidence of traumatic brain injury among children in the United States - differences by race. J. Head Trauma Rehabil. 20, 229-238. doi: 10.1097/00001199-20050500000006

Lee, S. W., Gajavelli, S., Spurlock, M. S., Andreoni, C., de Rivero Vaccari, J. P., Bullock, M. R., et al. (2018). Microglial inflammasome activation in penetrating ballistic-like brain injury. J Neurotrauma 35, 1681-1693. doi: 10.1089/neu.2017. 5530

Lei, P., Li, Y., Chen, X., Yang, S., and Zhang, J. (2009). Microarray based analysis of microRNA expression in rat cerebral cortex after traumatic brain injury. Brain Res. 1284, 191-201. doi: 10.1016/j.brainres.2009.05.074

Lei, X., Lei, L., Zhang, Z., Zhang, Z., and Cheng, Y. (2015). Downregulated miR-29c correlates with increased BACE1 expression in sporadic Alzheimer's disease. Int. J. Clin. Exp. Pathol. 8, 1565-1574.

Liu, C. G., Wang, J. L., Li, L., Xue, L. X., Zhang, Y. Q., and Wang, P. C. (2014b). MicroRNA-135a and -200b, potential Biomarkers for Alzheimers disease, regulate beta secretase and amyloid precursor protein. Brain Res. 1583, 55-64. doi: 10.1016/j.brainres.2014.04.026

Liu, L., Sun, T., Liu, Z., Chen, X., Zhao, L., Qu, G., et al. (2014a). Traumatic brain injury dysregulates microRNAs to modulate cell signaling in rat hippocampus. PLoS One 9:e103948. doi: 10.1371/journal.pone.0103948

Lu, X. C., Shear, D. A., Deng-Bryant, Y., Leung, L. Y., Wei, G., Chen, Z., et al. (2016). Comprehensive evaluation of neuroprotection achieved by extended selective brain cooling therapy in a rat model of penetrating ballistic-like brain injury. Ther. Hypotherm. Temp. Manag. 6, 30-39. doi: 10.1089/ther.2015.0017

Maciotta, S., Meregalli, M., and Torrente, Y. (2013). The involvement of microRNAs in neurodegenerative diseases. Front. Cell Neurosci. 7:265. doi: 10.3389/fncel.2013.00265

Madathil, S. K., Carlson, S. W., Brelsfoard, J. M., Ye, P., D’Ercole, A. J., and Saatman, K. E. (2013). Astrocyte-specific overexpression of insulin-like growth factor-1 protects hippocampal neurons and reduces behavioral deficits following traumatic brain injury in mice. PLoS One 8:e67204. doi: 10.1371/ journal.pone.0067204
Madathil, S. K., Deng-Bryant, Y., Wilfred, B. S., Leung, L. Y., Gilsdorf, J. S., and Shear, D. A. (2017). Alterations in brain-derived neurotrophic factor and insulin-like growth factor-1 protein levels after penetrating ballistic-like brain injury in rats. J. Trauma Acute Care Surg. 83(1 Suppl. 1), S16-S24. doi: 10.1097/ TA.0000000000001471

Madathil, S. K., and Saatman, K. E. (2015). "IGF-1/IGF-R signaling in traumatic brain injury: impact on cell survival, neurogenesis, and behavioral outcome," in Brain Neurotrauma: Molecular, Neuropsychological, and Rehabilitation Aspects, ed. F. H. Kobeissy (Boca Raton, FL: CRC Press).

Martin-Alonso, A., Cohen, A., Quispe-Ricalde, M. A., Foronda, P., Benito, A., Berzosa, P., et al. (2018). Differentially expressed microRNAs in experimental cerebral malaria and their involvement in endocytosis, adherens junctions, FoxO and TGF-beta signalling pathways. Sci. Rep. 8:11277. doi: 10.1038/ s41598-018-29721-y

Mendez, M. F., Paholpak, P., Lin, A., Zhang, J. Y., and Teng, E. (2015). Prevalence of traumatic brain injury in early versus late-onset Alzheimer's disease. J. Alzheimers Dis. 47, 985-993. doi: 10.3233/Jad-143207

Mestdagh, P., Hartmann, N., Baeriswyl, L., Andreasen, D., Bernard, N., Chen, C., et al. (2014). Evaluation of quantitative miRNA expression platforms in the microRNA quality control (miRQC) study. Nat. Methods 11, 809-815. doi: 10.1038/nmeth.3014

Mestdagh, P., Van Vlierberghe, P., De Weer, A., Muth, D., Westermann, F., Speleman, F., et al. (2009). A novel and universal method for microRNA RTqPCR data normalization. Genome Biol. 10:R64. doi: 10.1186/gb-2009-10-6r64

Meyer, K. S., Marion, D. W., Coronel, H., and Jaffee, M. S. (2010). Combat-related traumatic brain injury and its implications to military healthcare. Psychiatr. Clin. N. Am. 33, 783-796. doi: 10.1016/j.psc.2010.08.007

Mondello, S., Shear, D. A., Bramlett, H. M., Dixon, C. E., Schmid, K. E., and Dietrich, W. D. (2016). Insight into pre-clinical models of traumatic brain injury using circulating brain damage biomarkers: operation brain trauma therapy. J. Neurotrauma 33, 595-605. doi: 10.1089/neu.2015.4132

Mountney, A., Bramlett, H. M., Dixon, C. E., Mondello, S., Dietrich, W. D., Wang, K. K. W., et al. (2016). Simvastatin treatment in traumatic brain injury: operation brain trauma therapy. J. Neurotrauma 33, 567-580. doi: 10.1089/neu. 2015.4130

Muresan, V., Varvel, N. H., Lamb, B. T., and Muresan, Z. (2009). The cleavage products of amyloid-beta precursor protein are sorted to distinct carrier vesicles that are independently transported within neurites. J. Neurosci. 29, 3565-3578. doi: 10.1523/JNEUROSCI.2558-08.2009

Nelson, P. T., Wang, W. X., and Rajeev, B. W. (2008). MicroRNAs (miRNAs) in neurodegenerative diseases. Brain Pathol. 18, 130-138. doi: 10.1111/j.17503639.2007.00120.x

Nguyen, K. V. (2019). $\beta$-Amyloid precursor protein (APP) and the human diseases. AIMS Neuroscience 6, 273-281. doi: 10.3934/Neuroscience.2019. 4.273

Niederst, E. D., Reyna, S. M., and Goldstein, L. S. (2015). Axonal amyloid precursor protein and its fragments undergo somatodendritic endocytosis and processing. Mol. Biol. Cell 26, 205-217. doi: 10.1091/mbc.E14-06-1049

Parvathy, S., Hussain, I., Karran, E. H., Turner, A. J., and Hooper, N. M. (1999). Cleavage of Alzheimer's amyloid precursor protein by alpha-secretase occurs at the surface of neuronal cells. Biochemistry 38, 9728-9734. doi: 10.1021/ bi9906827

Plassman, B. L., Havlik, R. J., Steffens, D. C., Helms, M. J., Newman, T. N., Drosdick, D., et al. (2000). Documented head injury in early adulthood and risk of Alzheimer's disease and other dementias. Neurology 55, 1158-1166. doi: 10.1212/Wnl.55.8.1158

Purushothuman, S., Marotte, L., Stowe, S., Johnstone, D. M., and Stone, J. (2013). The response of cerebral cortex to haemorrhagic damage: experimental evidence from a penetrating injury model. PLoS One 8:e0059740. doi: 10.1371/ journal.pone.0059740

Redell, J. B., and Dash, P. K. (2007). Traumatic brain injury stimulates hippocampal catechol-O-methyl transferase expression in microglia. Neurosci. Lett. 413, 36-41. doi: 10.1016/j.neulet.2006.11.060

Redell, J. B., Zhao, J., and Dash, P. K. (2011). Altered expression of miRNA-21 and its targets in the hippocampus after traumatic brain injury. J. Neurosci. Res. 89, 212-221. doi: 10.1002/jnr.22539 
Roberts, G. W., Gentleman, S. M., Lynch, A., Murray, L., Landon, M., and Graham, D. I. (1994). Beta amyloid protein deposition in the brain after severe head injury: implications for the pathogenesis of Alzheimer's disease. J. Neurol. Neurosurg. Psychiatr. 57, 419-425. doi: 10.1136/jnnp.57.4.419

Santiago, L. A., Oh, B. C., Dash, P. K., Holcomb, J. B., and Wade, C. E. (2012). A clinical comparison of penetrating and blunt traumatic brain injuries. Brain Injury 26, 107-125. doi: 10.3109/02699052.2011.635363

Savonenko, A. V., Melnikova, T., Laird, F. M., Stewart, K. A., Price, D. L., and Wong, P. C. (2008). Alteration of BACE1-dependent NRG1/ErbB4 signaling and schizophrenia-like phenotypes in BACE1-null mice. Proc. Natl. Acad. Sci. U.S.A. 105, 5585-5590. doi: 10.1073/pnas.0710373105

Schonrock, N., Matamales, M., Ittner, L. M., and Gotz, J. (2012). MicroRNA networks surrounding APP and amyloid-beta metabolism - implications for Alzheimer's disease. Exp. Neurol. 235, 447-454. doi: 10.1016/j.expneurol.2011. 11.013

Segall, S. K., Shabalina, S. A., Meloto, C. B., Wen, X., Cunningham, D., Tarantino, L. M., et al. (2015). Molecular genetic mechanisms of allelic specific regulation of murine Comt expression. Pain 156, 1965-1977. doi: 10.1097/j. pain.0000000000000258

Shear, D. A., Williams, A. J., Sharrow, K., Lu, X. C., and Tortella, F. C. (2009). Neuroprotective profile of dextromethorphan in an experimental model of penetrating ballistic-like brain injury. Pharmacol. Biochem. Behav. 94, 56-62. doi: 10.1016/j.pbb.2009.07.006

Shin, R. W., Ogino, K., Kondo, A., Saido, T. C., Trojanowski, J. Q., Kitamoto, T., et al. (1997). Amyloid beta-protein (Abeta) 1-40 but not Abeta1-42 contributes to the experimental formation of Alzheimer disease amyloid fibrils in rat brain. J. Neurosci. 17, 8187-8193. doi: 10.1523/JNEUROSCI.17-21-08187. 1997

Shin, S. D., Shin, A., Mayagoitia, K., Siebold, L., Rubini, M., Wilson, C. G., et al. (2019). Loss of amyloid precursor protein exacerbates early inflammation in Niemann-Pick disease type C. J. Neuroinflamm. 16:269. doi: 10.1186/s12974019-1663-5

Shioya, M., Obayashi, S., Tabunoki, H., Arima, K., Saito, Y., Ishida, T., et al. (2010). Aberrant microRNA expression in the brains of neurodegenerative diseases: miR-29a decreased in Alzheimer disease brains targets neurone navigator 3. Neuropathol. Appl. Neurobiol. 36, 320-330. doi: 10.1111/j.1365-2990.2010. 01076.x

Taylor, C. A., Bell, J. M., Breiding, M. J., and Xu, L. K. (2017). Traumatic brain injury-related emergency department visits, hospitalizations, and Deaths United States, 2007 and 2013. MMWR Surveill. Summ. 66, 1-18. doi: 10.15585/ mmwr.ss6609a1

Thounaojam, M. C., Kaushik, D. K., and Basu, A. (2013). MicroRNAs in the brain: it's regulatory role in neuroinflammation. Mol. Neurobiol. 47, 1034-1044. doi: 10.1007/s12035-013-8400-3

Tran, H. T., LaFerla, F. M., Holtzman, D. M., and Brody, D. L. (2011). Controlled cortical impact traumatic brain injury in $3 \mathrm{xTg}-\mathrm{AD}$ mice causes acute intra-axonal amyloid-beta accumulation and independently accelerates the development of tau abnormalities. J. Neurosci. 31, 9513-9525. doi: 10.1523/ JNEUROSCI.0858-11.2011

Truettner, J. S., Motti, D., and Dietrich, W. D. (2013). MicroRNA overexpression increases cortical neuronal vulnerability to injury. Brain Res. 1533, 122-130. doi: 10.1016/j.brainres.2013.08.011

Vassar, R., Bennett, B. D., Babu-Khan, S., Kahn, S., Mendiaz, E. A., Denis, P., et al. (1999). Beta-secretase cleavage of Alzheimer's amyloid precursor protein by the transmembrane aspartic protease BACE. Science 286, 735-741. doi: 10.1126/ science.286.5440.735

Veitch, D. P., Friedl, K. E., and Weiner, M. W. (2013). Military risk factors for cognitive decline, dementia and Alzheimer's disease. Curr. Alzheimer Res. 10, 907-930. doi: 10.2174/15672050113109990142

Wahrle, S. E., Jiang, H., Parsadanian, M., Kim, J., Li, A., Knoten, A., et al. (2008). Overexpression of ABCA1 reduces amyloid deposition in the PDAPP mouse model of Alzheimer disease. J. Clin. Invest. 118, 671-682. doi: 10.1172/JCI33622

Wang, W. X., Visavadiya, N. P., Pandya, J. D., Nelson, P. T., Sullivan, P. G., and Springer, J. E. (2015). Mitochondria-associated microRNAs in rat hippocampus following traumatic brain injury. Exp. Neurol. 265, 84-93. doi: 10.1016/j. expneurol.2014.12.018

Williams, A. J., Bautista, C. C., Hartings, J. A., Lu, X. M., Rolli, M. L., and Tortella, F. C. (2005). Penetrating ballistic brain injury (PBBI) in the rat: differential time course of cell death, axonal degeneration, hemorrhage, and inflammation. J. Neurotrauma 22, 1185-1185.

Williams, A. J., Ling, G. S. F., and Tortella, F. C. (2006). Severity level and injury track determine outcome following a penetrating ballistic-like brain injury in the rat. Neurosci. Lett. 408, 183-188. doi: 10.1016/j.neulet.2006.08.086

Yu, F., Zhang, Y., and Chuang, D. M. (2012). Lithium reduces BACE1 overexpression, beta amyloid accumulation, and spatial learning deficits in mice with traumatic brain injury. J. Neurotrauma 29, 2342-2351. doi: 10.1089/neu. 2012.2449

Zaloshnja, E., Miller, T., Langlois, J. A., and Selassie, A. W. (2008). Prevalence of Long-Term Disability From Traumatic Brain Injury in the Civilian Population of the United States, 2005. J. Head Trauma Rehabil. 23, 394-400. doi: 10.1097/ 01.Htr.0000341435.52004.Ac

Zhang, L., Song, L., Terracina, G., Liu, Y., Pramanik, B., and Parker, E. (2001). Biochemical characterization of the gamma-secretase activity that produces beta-amyloid peptides. Biochemistry 40, 5049-5055. doi: 10.1021/bi0028800

Zhang, Y. W., Thompson, R., Zhang, H., and Xu, H. (2011). APP processing in Alzheimer's disease. Mol. Brain 4:3. doi: 10.1186/1756-6606-4-3

Zong, Y., Wang, H., Dong, W., Quan, X., Zhu, H., Xu, Y., et al. (2011). miR-29c regulates BACE1 protein expression. Brain Res. 1395, 108-115. doi: 10.1016/j.brainres.2011.04.035

Disclaimer: AMB is the owner/founder of Aries Biotechnologies (Oakland, CA, United States), which had no role in this work. Material has been reviewed by the Walter Reed Army Institute of Research. There is no objection to its presentation and/or publication. The opinions or assertions contained herein are the private views of the author, and are not to be construed as official, or as reflecting true views of the Department of the Army or the Department of Defense.

Conflict of Interest: The authors declare that the research was conducted in the absence of any commercial or financial relationships that could be construed as a potential conflict of interest.

Copyright (c) 2020 Thangavelu, Wilfred, Johnson, Gilsdorf, Shear and Boutté. This is an open-access article distributed under the terms of the Creative Commons Attribution License (CC BY). The use, distribution or reproduction in other forums is permitted, provided the original author(s) and the copyright owner(s) are credited and that the original publication in this journal is cited, in accordance with accepted academic practice. No use, distribution or reproduction is permitted which does not comply with these terms. 